\title{
A Recent Review on Phytochemical Constituents and Medicinal Properties of Mimosa rubicaulis Lam
}

\author{
A. M. Tamboli*1, Dr. K. A. Wadkar ${ }^{2}$
}

1Department of Pharmaceutical Chemistry, Sahyadri college of Pharmacy, Methwade, Maharashtra, India

${ }^{2}$ Department of Pharmacognosy, Appasaheb Birnale College of Pharmacy, Sangli. Maharashtra, India Corresponding Author’s E-mail: ashpak.tamboli@gmail.com

\section{ABSTRACT}

In the developing world the trend has been changed from synthetic to natural medicine. Trees and plants are sources of many medicines. The use of medicinal plants was compiled in Ayurveda which listed more than 8000 herbal remedies. Mimosa rubicaulis Lam belonging to the family Fabaceae and subfamily Mimosoideae. It is bipinnately compound, each leaf having 8-12 pairs of pinnae, each with 16-20 pairs of pinnules, unlike this plant is having good potential activity in plant due to it has been attributed to their flavanoid and sterol contents. Several flavanoids isolated from these plants have been discovered to possess significant Various Pharmacological activity. Literature review reports the presence of flavanoids, triterpenoids, phytosterols and alkaloids in Mimosa rubicaulis Lam.

Keywords : Mimosa rubicaulis Lam, Phytochemical constituents, Medicinal Properties, Gentianaceae

\section{INTRODUCTION}

Mimosa rubicaulis Lam is Commonly Known as Sankhvel, In Hindi: Kacheyta, kinglu, shiah-kanta InTelugu: Kodimudusu chettu. In Nepal, the Chepang community is using Mimosa rubicaulis Lam roots for sprains, abdominal spasms and wounds. Powdered root is given for vomiting and bruised leaves are applied to burn. Smoke arising from burning the gum is disinfectant. It is a large straggling shrub which is very prickly. It sports long clusters of many pink spherical flower-heads which are 1-1.5 cm across. Flowers pink fading to White, tetramerous in globose pedunculate heads $1.25-1.5 \mathrm{~cm}$. diameter peduncles 2.5-5 cm long, pubescent in axillary in the axial of a small, linear spathulate, ciliate bract. The plant Mimosa rubicaulis Lam was collected in the month of June 2013 from in and around Tirupathi, Chittor district, Andhra Pradesh, India. Mimosa rubicaulis is a large, straggling, very prickly shrub. It flowers from June to September, sporting long clusters of many pink spherical flower heads $1-1.5 \mathrm{~cm}$ across. The flowers fade to white, so the clusters sport both pink and white flower-heads most of the time. Leaves are double-compound, 8-15 cm long, with thorny rachis. Leaves have 3-2 pairs of side-stalks, each with 6-15 pairs of tiny oblong leaflets $4-8 \mathrm{~mm}$. Pods are thin, flat, curved, $8-13 \mathrm{~cm}$ long, $1 \mathrm{~cm}$ wide, breaking into 4-10 rectangular single-seeded units, leaving the remains of the pod attached to the shoot. It is considered useful for hedges. The wood is suitable for tent pegs and for making gun powder charcoal. Roots and leaves are used medicinally. Himalayan Mimosa is found in the Himalayas, from Afghanistan to Bhutan, at altitudes of 300-1900 m. It prefers forest edges and boundaries of fields and gardens..$^{(1,2,3)}$ 
Traditionally Mimosa rubicaulis Lam. Had higher value in treating of various diseases like laxative, leucoderma, leprosy, chronic diarrhea, Rheumatism, Anti diabetic, Treatment of snake bites, Anti-fungal agent, Used for cuts \& wounds (had wound healing property). As we know that generally natural origin compounds had less side effects and less toxic when compared with synthetic compounds. The roots and leaves are widely used in Indian folk medicine for treating piles, bruises, burns diabetics, antiemetic agent ${ }^{(4,5)}$ several phytoconstituents were observed from the plant earlier.

In the early 1800 s, an emerging fascination with such molecules give rise to the field of organic chemistry, so named for its emphasis on the chemistry of living things. Later discrete organic compounds were discovered and were known as 'natural products' or 'secondary metabolites'. In particular, higher plants have been the source of medicinal agents since the earliest times and today they continue to play a dominant role in the primary health care of about $80 \%$ of the world's population. In spite of overwhelming influence of modern medicine and tremendous advances made in the population of synthetic drugs, traditional medicament referred to now a day as herbal drugs in different places in literature, have retained their place in therapy. Their effectiveness, low cost and comparative freedom from serious toxic effects make these medicaments not only popular but also an accepted mode of treating disease even in developed countries.

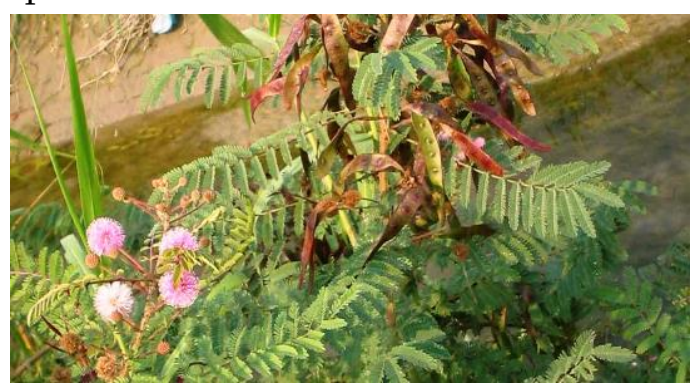

Figure 1: Image of Mimosa rubicaulis Lam.
Kingdom: Plantae

Division: Angiosperms

Class: Eudicots.

Order: Fabales.

Family: Fabaceae.

Genus:Mimosa

Species: rubicaulis

\section{PHYTOCHEMICAL CONSTITUENTS}

Table 1. Phytochemical constituents of Mimosa rubicaulis Lam

\begin{tabular}{|l|l|}
\hline $\begin{array}{l}\text { Name of } \\
\text { Mant }\end{array}$ & Name of Phytochemical constituents \\
\hline Leaves & $\begin{array}{l}\text { flavonoid compounds like quercetin, } \\
\text { luteolin, 5,7,4 '-trihydroxy-6,3',5'- } \\
\text { trimethoxy-flavone,7-O-alpha-L- } \\
\text { arabinopyranosyl(1->6)-O-beta-D- } \\
\text { lucopyranoside and tannins, 4- } \\
\text { ethylgallic acid,. }\end{array}$ \\
\hline Root & $\begin{array}{l}\text { Triterpenes, steroids, flavonoids, } \\
\text { tannins, carbohydrates and alkaloids } \\
\text { B-Sitosterol, 4-Dihydoxy-3-methoxy } \\
\text { cinnamic acid, Octadecanoic acid }\end{array}$ \\
\hline Stem & Phenol, flavonoids. \\
\hline
\end{tabular}

\section{MEDICINAL PROPERTIES}

Various studies have revealed the different pharmacological potentials of Mimosa rubicaulis Lam both in vitro and in vivo test models. Mimosa rubicaulis Lam has demonstrated to possess, antibacterial, Anti-inflammatory, Hypoglycemic Activity, Antitumor activity and antioxidant activities. These properties have been described in greater detail in the following subsections. ${ }^{(6)}$ 


\section{Antibacterial activity:-}

Resistance of many bacteria against antibiotics is alarmingly increasing and the side effects associated with the usage of antibiotics are also a major problem in treatment of infectious diseases. Therefore, search for new substances with antimicrobial activity has become an urgent necessity. Medicinal plants have been used in development of drugs from long time and compounds with antimicrobial activity from plant origin are the possible.

The current study was to investigate the presence of Anti-Bacterial activity on the different root extracts of Mimosa rubicaulis Lam. The extracts obtained using continuous hot percolation method and antibacterial activity tested by using cup plate method. The present investigation reveals that all the three extracts namely ethyl acetate, methanol and water extracts of concentration $1000 \mathrm{mcg} / \mathrm{ml}$ showing antibacterial activity against both gram + ve and gram ve organisms. Among all the three extracts root methanolic extract showing more anti-bacterial activity. The study shown that the all the three root extracts of Mimosa rubicaulis Lam. Possess AntiBacterial activity. ${ }^{(7)}$

\section{Anti-inflammatory activity:-}

Among the four extracts of Mimosa rubicaulis the ethyl acetate extract showed better activity than other extracts on the superoxide, hydroxyl and DPPH free radicals. The order of activity was in the following manner: Ascorbic acid> ethyl acetate extract $>$ methanol extract $>$ Hydro-alcoholic extract $>$ hexane extract. The anti-inflammatory activity of different extracts of Mimosa rubicaulis on carrageenan induced paw oedema in rats. Acute oral toxicity studies reveal that the different extracts up to $2000 \mathrm{mg} / \mathrm{kg}$ have not produced any mortality in experimental animals.

The ethyl acetate and methanolic extracts of Mimosa rubicaulis roots at the doses of 100, 200 and 400 $\mathrm{mg} / \mathrm{kg}$ were produced significant $(\mathrm{P}<0.001)$ reduction when compared to drug vehicle treated control group. The hydroalcoholic and hexane extracts of Mimosa rubicaulis tested, at the doses of 100, 200 and 400 $\mathrm{mg} / \mathrm{kg}$ were exhibited significant $(\mathrm{p}<0.05)$ activity. The percentage inhibition of the maximal paw oedema during $6 \mathrm{~h}$ for the hydroalcoholic extracts of Mimosa rubicaulis at $400 \mathrm{mg} / \mathrm{kg}$. The percentage inhibition of the maximal paw oedema during $6 \mathrm{~h}$ for the methanolic extracts Mimosa rubicaulis at 400 $\mathrm{mg} / \mathrm{kg}$. The percentage inhibition of the maximal paw oedema during $6 \mathrm{~h}$ for the ethyl acetate extracts of Mimosa rubicaulis at $400 \mathrm{mg} / \mathrm{kg}$.

\section{Hypoglycemic Activity:-}

The anti-diabetic screening of the hydroalcoholic extract of M.rubicaulis leaves was studied on both alloxan induced diabetic rats and normoglycaemic rats ${ }^{(8-9)}$.The acclimatized animals were kept fasting for $24 \mathrm{~h}$ with water adlibitum and injected intraperitoneally a dose of $120 \mathrm{mg} / \mathrm{kg}$ of alloxan monohydrate in normal saline. After one hour, the animals were provided feed ad libitum. The blood glucose level was checked before alloxanisation and $24 \mathrm{~h}$ after alloxanisation by withdrawing blood from the tip of the tail of each rat under mild ether anesthesia. The blood glucose level was measured with haemoglucostrips supplied by $\mathrm{M} / \mathrm{s}$ Pulsatum Health Care Pvt. Ltd., Bangalore with the help of a Pulsatum blood glucose monitor. Animals were considered diabetic when the blood glucose level was raised beyond twice the value of normal. This condition was observed at the end of $48 \mathrm{~h}$ after alloxanisation. The animals were segregated into four groups of six rats in each. Group-I served as control and received vehicle $(2 \mathrm{ml} / \mathrm{kg})$ through oral route. Group-II received Glibenclamide (2.5 mg/kg). GroupIII and IV received the extract at doses of 200 and $400 \mathrm{mg} / \mathrm{kg}$ in a similar manner. Blood samples were collected from each rat by cutting the tip of the tail 
under mild ether anesthesia. Blood glucose level was estimated at 0 h, 1 h, 2 h, $4 \mathrm{~h}$ and 8 h respectively. ${ }^{(10)}$

\section{Antitumor activity:-}

The World cancer report documents that cancer rates are set to increase at an alarming rate globally. Cancer rates could increase by $50 \%$ new cases for the year 2020. The antitumor activity of the methanol stem extract of Mimosa rubicaulis Lam (MEMR) was evaluated against Ehrlich Ascites Carcinoma (EAC) tumor model in Swiss albino mice. After 24h of intraperitoneal inoculation of tumor (EAC) cells in mice, MEMR was administered at the dose of 100, 200 and 400mg per kg body weight orally for 13 consecutive days. After $24 \mathrm{~h}$ of the last dose and followed by eighteen hours of fasting, mice were sacrificed and antitumor effect of MEMR extract on EAC bearing mice was assessed by evaluating tumor volume, viable and nonviable tumor cell count, mean survival time, percentage of increase in life span and hematological parameters of EAC bearing host. MEMR showed significant $(\mathrm{p}<0.0001)$ decrease in tumor volume, viable cell count, percentage of increase in life span of EAC bearing mice. Haematological profile such as RBC, WBC, Haemoglobin, PCV (packed cell volume) levels restored to more or less normal level in MEMR treated mice as compared to EAC control. Effect of MEMR on viability of cancer cell lines (such as EAC, MCF-7, MDA-MB 435S) was evaluated by XTT assay, MEMR exhibited significant effect on cell viability. Apoptosis in EAC cell line was evaluated by DNA laddering assay, EAC cells treated with MEMR exhibited a characteristic "ladder" pattern after Separation of the fragments by agarose gel electrophoresis and subsequent visualization, by ethidium bromide staining. Therefore, from the results of the present study it can be concluded that MEMR exhibited significant anti-tumor activity against Ehrlich ascites carcinoma (EAC) in Swiss albino mice. The XTT assay and DNA laddering results indicate that MEMR exhibited cytotoxic effect on EAC, MCF-7, MDA-MB 435S cell lines and induced Apoptosis in EAC cell line. ${ }^{(11,12,)}$

\section{Antioxidant activity:-}

The antioxidant activities of the prepared plant extract were investigated by using two methods. DPPH radical Scavenging assay and reduction ability ferric to ferrous assay. DPPH Scavenging assay has wide application in determining radical Scavenging activity of antioxidant. ${ }^{(14)}$ Extract of Mimosa rubicaulis Lam Showed significant radical Scavenging activity with IC50 Value Close to that of standard, ascorbic acid. The ability of these extract to Scavenge DPPH Free radicals Suggest that they might be electron donors and react with free radical to convert them to more stable products and terminate radical Chain. In this study the hydrogen atom or electron donation ability of each plant extract against DPPH free radical was measured from bleaching of violet colored DPPH solution at $517 \mathrm{~nm}$. DPPH radical Scavenging activity of each sample. ${ }^{(13)}$

\section{DISCUSSION}

Medicinal plants have provided leads to combat diseases since the dawn of civilization. From screening the classics of Brihattrayi and Nighantu, it becomes clear that Mimosa rubicaulis Lam has been used to treat a wide range of diseases. Since most of the pharmacological activities of Mimosa rubicaulis Lam were limited to animal model, clinical trials of individual as well as compound formulations should be conducted in order to establish their safety and effectiveness. Mimosa rubicaulis Lam isused as an antioxidant and antimicrobial. In the earlier studies, it was found that Mimosa rubicaulis lam extracts of root and stem showed anti-microbial activity. This preliminary study was carried out to evaluate anticancer activity of Mimosa rubicaulis Lam. Based on 
in vivo results it can be concluded that the life span of EAC tumor bearing mice was increased which is a reliable criteria for judging the value of anti-cancer drug. Based on in-vitro results it can be concluded that MEMR exhibited cytotoxic effect on cancer cells and based DNA laddering assay it can be concluded that MEMR induced apoptosis in EAC cells. Since no negative Mimosa rubicaulis Lam drug interaction is reported till date, more studies in this area remain yet to be accomplished. A consorted therapeutic approach by linking Mimosa rubicaulis Lam and synthetic drugs will be highly desirable. Though the herb is considered to be safe in the dosage mentioned, potent curative effects of the plant against particular human aliments need to be verified by more controlled and exhaustive clinical trials. To summarise the scattered knowledge in ancient and contemporary literature, it is needed to highlight the entities which are worthy of further investigation leading to the drug developments.

\section{CONCLUSION}

Mimosa rubicaulis Lam exhibits antioxidant and laxative activities and Anti-Bacterial Investigation on the different Root Extracts of Mimosa rubicaulis Lam we can conclude that Root extract of Mimosa rubicaulis Lam. has good Anti-Bacterial activity against Gram (+)ve and Gram(-)ve micro- organisms. Ibuprofen and ethyl acetate extract of Mimosa rubicaulis Lam significantly inhibited the maximal oedema response by carrageenan-induced rat paw acute inflammation. The present studies revealed that the hydroalcoholic extract of the leaves caused significant reduction in the blood glucose levels in the rats. The extract was found to produce marked reduction in blood glucose concentration. The drug possesses multiple-target actions and several therapeutic claims by virtue of its various active phytomolecules. Contemporary experimental and clinical studies confirm and establish the Ayurvedic therapeutic validation of the herb. Future experiments involving large sample size and in depth cause-effect evaluations would be more confirmatory.

\section{REFERENCES}

[1]. Anonymous, In; The Wealth of india 1994; A Dictionary of Indian Raw Materials and industrial products 2nd Ed.VOL-II B. PID (CSIR), New Delhi;pp.53.

[2]. Kirtikar KR \& Basu B.D. 1935 Indian Medicinal Plants, Second edition Lalit Mohan Basu, Allahabad, pp 918.

[3]. Nandipati et al 2014 International Journal of Pharmaceutical Sciences and Research.,IJPS; Vol. 5(4): pp.1514-1524.

[4]. Amir Muhammad Khan Rizwana Aleem Qureshi, Faizan Ullah, Syed Aneel Gilani, , Phytochemical analysis of selected medicinal plants of Margalla Hills and surroundings, Journal of Medicinal Plants Research, 9 November, 2011; 5(25): pp 6017-6023.

[5]. Prema Chandra Sekhar, Y. Vijay Kumar (2012) International Journal of Ayurvedic and Herbal...Medicine 2:5 (2012)pp 803:809.

[6]. Paritala Vikram et al 2014 4(1) Asian Pacific Journal of Tropical Biomedicine pp.931-935.

[7]. Amarnath Reddy Ganji*, Anil Chowdary Yedla, Ravi P, Madhava Reddy P V. International Journal of Pharmacognosy and Phytochemical Research 2010; 2(4):pp18-21.

[8]. Mohammad FA, Syed Md K, Syed SG, Syed SM, Shaik RA, Shaik M A, Mohammad I.Anti diabetic activity of Vinca rosea extracts in alloxan induced diabetic rats.International Journal of Endocrinology, 2010; 6: pp1-6.

[9]. Stalin C, Dinesh Kumar P, Nithyananthan K. Evaluation of antidiabetic activity ofmethanolic leaf extracts of Ficus carica in alloxan -induced 
diabetic rats. Asian $J$ of Pharmaceutical and Clinical Research, 2012; 5(3): pp 85-87.

[10]. Ram Mohan Manda1*, Ganapaty Seru2 European Journal of Biomedical and Pharmaceutical sciences 2015, Volume 2, Issue 1, pp.543-548.

[11]. M.N. Chowdary Nandipati*1, G. Sumalatha 1, Ch. Baburao 2, J. Ramesh Babu 3 and C. Sridevi 4 IJPSR, 2014; Vol. 5(4): pp1514-1524.

[12]. Marimuthu P. Projection of cancer incidence in five cities and cancer mortality in India.Ind J Cancer (2008); 45 (1):1-7.

[13]. Sabina Paranjuli, Nirmala Tilija pun, Shraddha parajuli, Nirmala Jamarkattel-pandit Antioxidant activity,Total Phenol and Flavonoid contant in Some Selected Medicinal Plants of Nepal JHAS 2012;Vol.2 No.1 pp.27-31.

[14]. Bhuiyan MAR,Hoque MZ,Hossain SJ, Free radical Scavenging activity of Zizyphus Mauritiana.World Journal of agricultural science 2009;5(3);pp..318-322.

\section{Cite this article as :}

A. M. Tamboli, Dr. K. A. Wadkar, "A Recent Review on Phytochemical Constituents and Medicinal Properties of Mimosa rubicaulis Lam", International Journal of Scientific Research in Science and Technology (IJSRST), Online ISSN : 2395-602X, Print ISSN : 2395-6011, Volume 6 Issue 2, pp. 300-305, March-April 2019. Available at doi : https://doi.org/10.32628/IJSRST196251 Journal URL : http://ijsrst.com/IJSRST196251 